\title{
Studi Rekonstruksi Permukaan Wajah Secara 3-Dimensi Menggunakan Metode Profilometri Frinji Digital
}

\author{
1,2Khawarizmi, Ryan Muhammad, 1,2Wisesa, Alvin Ekaputra, 1,2Suprijanto,\& 1,3 Juliastuti, Endang \\ 1Program Studi S1 Teknik Fisika, Fakultas Teknologi Industri, Institut Teknologi Bandung (ITB), Bandung, \\ Indonesia
}

2Laboratorium Instrumentasi Medik, Institut Teknologi Bandung (ITB), Bandung, Indonesia

3Laboratorium Instrumentasi Optik, Institut Teknologi Bandung (ITB), Bandung, Indonesia

rkhawarizmi@gmail.com, levrias@gmail.com,supri@tf.itb.ac.id,yuliast@tf.itb.ac.id

\begin{abstract}
Abstrak
Profilometri frinji digital merupakan sistem pengukuran kedalaman dan rekonstruksi secara 3-dimensi menggunakan cahaya berpola yang diproyeksikan pada obyek uji. Profilometri frinji digital menggunakan informasi deformasi fasa akibat bentuk obyek sebagai besaran yang diukur untuk rekonstruksi obyek. Pada penelitian ini, sistem profilometri frinji digital terdiri dari sebuah proyektor Digital Light Processing (DLP) untuk proyeksi pola frinji dan kamera digital sebagai perangkat perekaman citra obyek. Kemudian akan dilakukan konversi besaran fasa pada hasil rekonstruksi menjadi besaran kedalaman pada skala metrik.
\end{abstract}

Penelitian awal dilakukan untuk mencoba konfigurasi sistem profilometri frinji digital untuk berbagai jenis obyek 3-dimensi menggunakan berbagai tipe frekuensi. Hasil penelitian awal memberikan bahwa konfigurasi dapat merekonstruksi berbagai jenis obyek 3-dimensi dengan frekuensi frinji optimum senilai 7 cycle/100 piksel. Implementasi pada wajah manusia dilakukan pada dua naracoba yaitu naracoba A dan B dengan area uji akurasi berada pada daerah hidung. Ketelitian pengukuran kedalaman hidung antara hasil rekonstruksi dan ukuran aslinya mencapai 90\% untuk naracoba pA dan $88 \%$ untuk naracoba B. Analisa kualitatif terhadap bentuk hasil rekonstruksi wajah juga dilakukan untuk menilai proporsionalitas terhadap wajah sebenarnya. Berdasarkan analisa kualitatif dan kuantitatif, teknik profilometri frinji digital memiliki potensi yang besar untuk dimanfaatkan sebagai cara pengukuran serta rekonstruksi profil permukaan wajah.

Kata Kunci : rekonstruksi wajah 3-dimensi, profilometri frinji digital, phase shifting interferometry, phase unwrapping

\section{Pendahuluan}

Wajah memiliki profil permukaan yang unik karena terdiri dari berbagai bagian penyusun yang berbeda antara satu bagian dengan bagian yang lain. Bagianbagian penyusun wajah yang mudah diamati adalah mata, hidung dan mulut[1]. Bagian-bagian ini menjadi sebuah fitur penting agar mesin atau komputer dapat menganalisa kesesuaian wajah. Proses ini biasa disebut sebagai biometrik dengan metode facial recognition.
Prinsip identifikasi individu menggunakan facial recognition adalah pemrosesan citra wajah 2-dimensi. Citra wajah direkam oleh kamera kemudian diproses menandai fitur-fitur penting yang menjadi ciri khas. Proses identifikasi dilanjutkan dengan menganalisa kecocokan fitur-fitur penting tersebut dengan referensi asli pada database[2].

Sistem facial recognition dapat ditingkatkan ketelitiannya dengan adanya informasi kedalaman wajah. Secara tidak langsung, untuk mengukur ukuran kedalaman wajah, diperlukan proses rekonstruksi wajah secara 3-dimensi. Metode rekonstruksi permukaan wajah berbasis pada teknik pemindaian memanfaatkan sifat-sifat optis. Contohnya adalah teknik time of flight, pola moire, stereo-vision, pemindaian laser, dan interferometri[3].

Profilometri frinji digital adalah teknik pemindaian obyek secara 3-dimensi yang merupakan pengembangan dari interferometri yang menggunakan pola gelap-terang atau biasa disebut sebagai pola frinji. Pola frinji dengan kerapatan tertentu akan diproyeksikan ke obyek lalu akan direkam citranya oleh kamera. Citra hasil perekaman kemudian akan diolah oleh pemroses data menjadi sebuah bentuk 3-dimensi yang menyerupai obyek aslinya. Makalah ini lebih lanjut akan memaparkan penggunaan profilometri frinji digital untuk merekonstruksi permukaan wajah manusia secara utuh.

\section{Metode Perancangan}

\subsection{Rancangan Umum}

Awalnya, pola frinji dibuat menggunakan program pembangkit pola frinji. Kemudian frinji akan diproyeksikan menggukanan proyektor DLP. Proyeksi finji dilakukan dengan 4 buah pola frinji yang berbeda fasa masing-masing sebesar $\frac{\pi}{2}$ radian. Untuk setiap proyeksi dilakukan perekaman citra oleh kamera digital. Informasi profil obyek diperoleh setelah dilakukan pengolahan pada keempat citra hasil perekaman dengan PSI (Phase Shifting Interferometry) 4-step yang mengubah citra akuisisi dari besaran intensitas menjadi besaran fasa dalam bentuk citra fasa terlipat (wrapped phase). Kemudian dilakukan pemilihan ROI (Region of Interest) dan proses pembukaan lipatan fasa (phase unwrapping) untuk memperoleh infromasi fasa 
Seminar Nasional Instrumentasi, Kontrol dan Otomasi (SNIKO) 2015 Bandung, Indonesia, 10-11 Desember 2015

sesungguhnya atau fasa absolut dari citra fasa terlipat. Namun sebelum dilakukan proses Phase Unwrapping dilakukan perlu dilakukan estimasi kualitas fasa. Estimasi kualitas fasa ditujukan untuk mengetahui informasi keseluruhan dari citra fasa serta melakukan penapisan terhadap noise yang ada. Phase unwrapping yang digunakan berbasis metode global unwrapping yang dapat mengolah citra secara cepat[4]. Metode Phase Unwrapping tersebut adalah PUMA (Phase Unwrapping Max-Cut)[5]. Terakhir, informasi fasa absolut tersebut direkonstruksi menjadi profil 3 dimensi dari obyek dan dilakukan konversi besaran fasa menjadi kedalaman untuk dibandingkan dengan profil obyek riil. Gambar 1 dibawah mengilustrasikan diagram alir proses rekonstruksi permukaan wajah secara 3-dimensi.

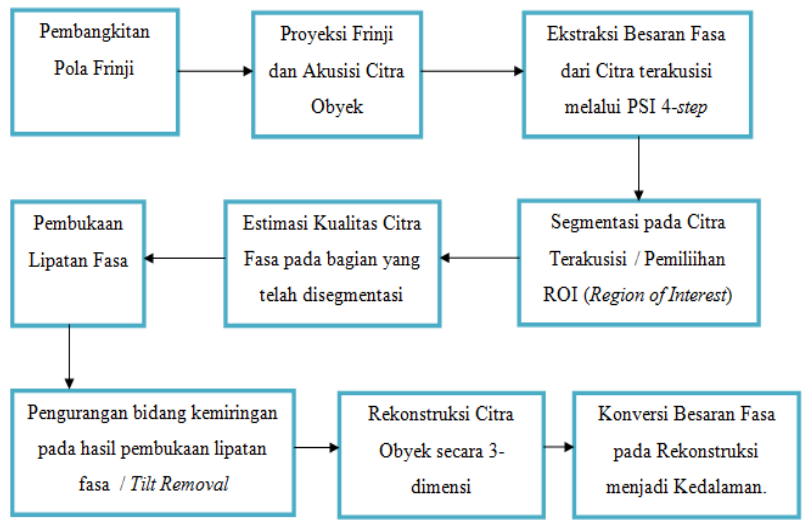

Gambar 1. Diagram alir penelitian profilometri frinji digital untuk rekonstruksi profil permukaan wajah secara 3-dimensi

\subsection{Rancangan Perangkat}

Sistem perangkat terdiri secara umum dari kamera digital, proyektor, dan komputer pengolah data. Konfigurasi sistem perangkat keras yang dirancang adalah jarak antara perangkat-perangkat pengukuran dengan obyek ukur. Proyektor diletakkan sejauh 184,1 $\mathrm{cm}$ dari latar secara tegak lurus. Kamera ditempatkan sejauh $188,2 \mathrm{~cm}$ terukur dari titik tengah gambar proyeksi dari proyektor. Jarak antara proyektor dengan kamera adalah $39 \mathrm{~cm}$ sehingga membentuk segitiga siku-siku sehingga memenuhi syarat triangulasi dengan sudut antara sebesar $12^{\circ}$. Sudut antara kamera digital dan proyektor optimum berada pada rentang $10-15^{\circ}$ untuk mengurangi efek bayangan pada obyek[6]. Susunan perangkat-perangkat keras pada sistem dapat dilihat pada Gambar 2.

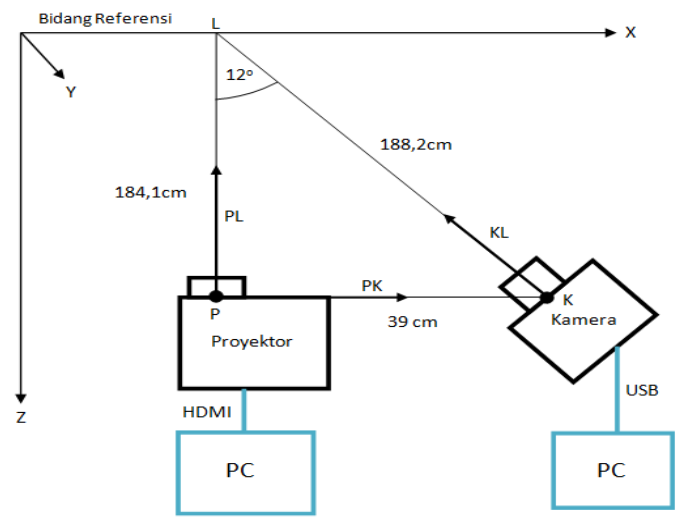

Gambar 2. Rancangan Perangkat Keras Sistem

Pengaturan cahaya pada ruang dan parameter pada perekaman sangat memengaruhi kualitas rekonstruksi obyek.Citra direkam pada kondisi ruang gelap agar citra yang diolah murni hanya citra frinji yang mengalami deformasi dari obyek. Perekaman citra dengan kondisi ruang bercahaya akan mengganggu pemrosesan citra selanjutnya. Parameter-parameter kamera kemudian diatur untuk mendapatkan citra obyek yang fokus. Parameter yang diatur adalah ISO sebesar 400, bukaan kamera sebesar $\mathrm{f} / 14$, dan shutter time selama $0,5 \mathrm{~s}$. Contoh citra terekam dari obyek rekonstruksi dapat dilihat pada Gambar 3.

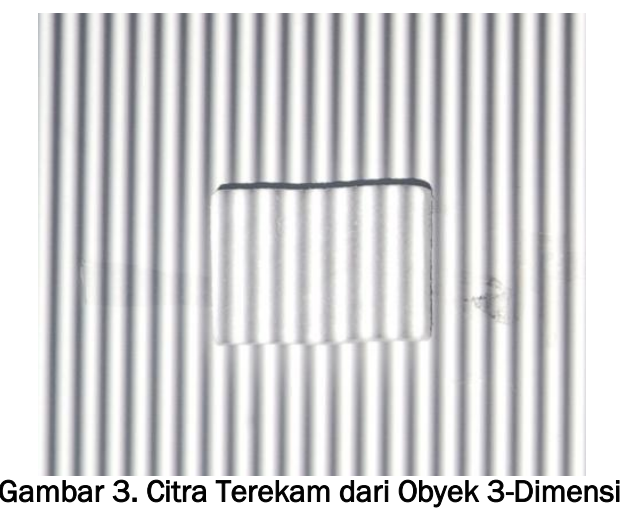

\subsection{Rancangan Penelitian}

Penelitian ini akan menguji pengaruh frekuensi frinji terhadap kualitas rekonstruksi obyek dan akurasi dari pengukuran tersebut. Dibangkitkan 4 tipe pola frinji dari kerapatan yang renggang sampai rapat. Frekuensifrekuensi frinji tersebut adalah 3,5,7,dan9 cycle/piksel. Penelitian awal dilakukan terlebih dahulu untuk beberapa obyek-obyek sederhana untuk meneliti kemampuan sistem merekonstruksi bentuk-bentuk yang merepresentasikan bagian pada wajah. Dipilih obyekobyek yaitu balok, benda-berundak, prisma segitiga, dan tabung untuk penelitian awal sistem. Bentuk-bentuk obyek uji diilustrasikan pada Gambar 4 dibawah. 


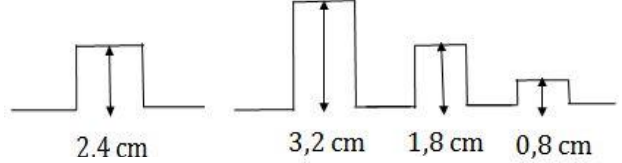

(a)

(b)



(c)

(d)

Gambar 4 Penampang Melintang dari Obyek Uji Peneltian Awal (a) Balok (b) Benda Berundak (c) Tabung (d) Prisma Segitiga

Pengujian frekuensi pada penelitian awal dilakukan dengan membandingkan kedalaman obyek antara nilai asli dari pengukuran dan nilai dari konversi fasakedalaman dari rekonstruksi obyek. Konversi besaran fasa-kedalaman mengikuti kaidah triangulasi dengan formula pada persamaan (1) dibawah dimana PL dan PK memiliki satuan $\mathrm{m}, \Omega$ merupakan fasa absolut dari hasil akhir rekonstruksi obyek 3-dimensi dengan satuan radian, $f$ dengan satuan linepairs per meter $(\mathrm{Ip} / \mathrm{m})$. Sehingga kedalaman profil obyek yaitu $z_{\text {konversi }}$ berada pada skala $\mathrm{m}$. Selain analisa ketelitian menggunakan perbandingan kedalaman, dilakukan analisa terhadap proporsionalitas kualitas hasil rekonstruksi.

$$
Z_{\text {konversi }}=\frac{P L \times \Omega}{2 \pi f \times P K}
$$

Melalui penelitian awal, didapatkan frekuensi optimum untuk rekonstruksi wajah. Setelah itu, dilakukan rekonstruksi pada wajah. Penilaian akurasi dilakukan pada bagian hidung naracoba. Nilai yang dibandingkan adalah jarak dari ujung hidung ke pangkal menggunakan meteran dan dari rekonstruksi. Jarak pangkal ke ujung hidung merupakan wujud dari kedalaman bagian wajah.

\section{Hasil dan Diskusi}

\subsection{Penelitian Awal}

Dilakukan rekonstruksi awal untuk obyek balok dengan keempat jenis frekuensi frinji yang dibangkitkan. Hasil rekonstruksi dapat dilihat pada Gambar 5-8. Sumbu z pada gambar menunjukan nilai fasa absolut dari hasil rekonstruksi yang sebanding dengan kedalaman obyek sesungguhnya. Melalui pengamatan, dapat dilihat rekonstruksi untuk frekuensi 9 cycle/100 piksel terdapat lonjakan yang tidak sesuai pada bagian atas balok. Rekonstruksi yang tidak sempurna ini diakibatkan oleh fake wrap[4] atau kesulitan pemrosesan citra terekam akibat frekuensi frinji yang terlalu rapat.

Nilai kedalaman obyek didapatkan melalui persamaan (1) sebelumnya. Kumpulan data untuk Rekonstruksi Balok ditampilkan pada Tabel 1. Dipilih frekuensi dengan ketelitian paling tinggi yakni untuk frekuensi 5 dan 7 untuk dilakukan pengujian kembali pada penelitian berikutnya. Penelitian selanjutnya adalah rekonstruksi untuk obyek berundak.

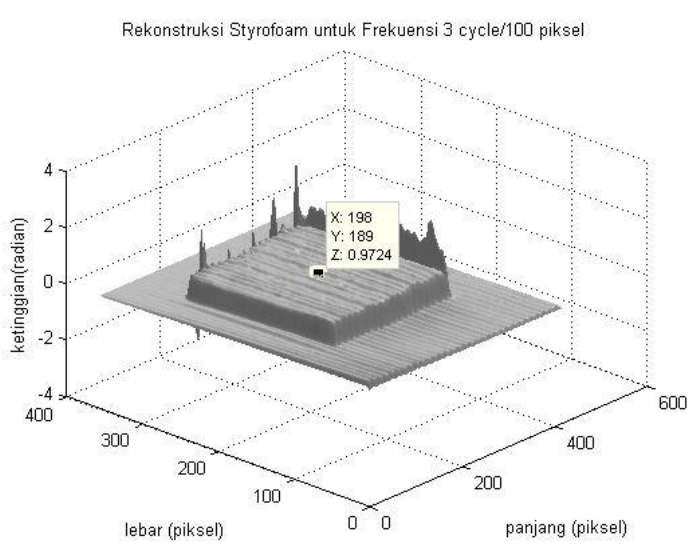

Gambar 5. Rekonstruksi pada Balok dengan Frekuensi 3 cycle/100 piksel

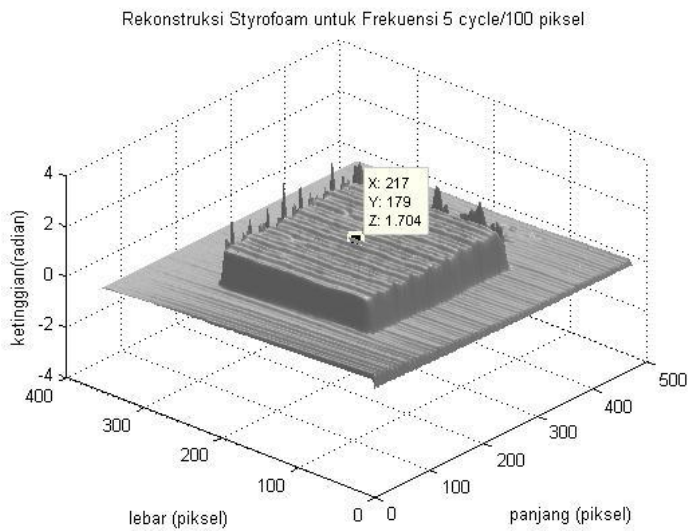

Gambar 6 Rekonstruksi pada Balok dengan Frekuensi 5 cycle/100 piksel

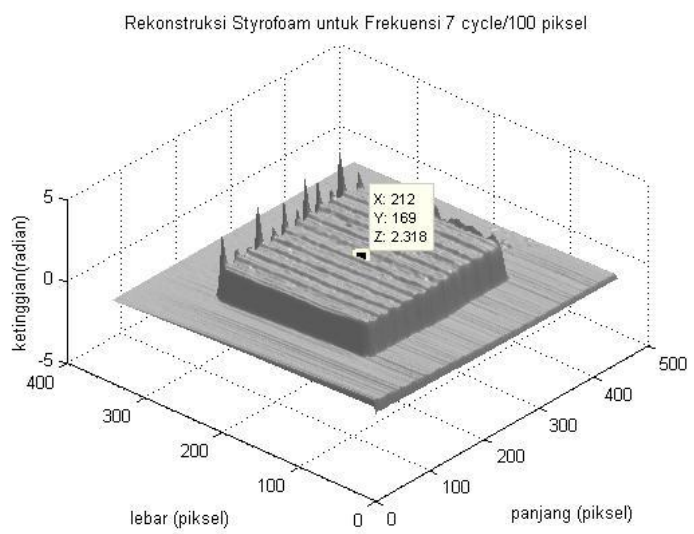

Gambar 7 Rekonstruksi pada Balok dengan Frekuensi 7 cycle/100 piksel 
Seminar Nasional Instrumentasi, Kontrol dan Otomasi (SNIKO) 2015 Bandung, Indonesia, 10-11 Desember 2015



Gambar 8 Rekonstruksi pada Balok dengan Frekuensi 9 cycle/100 piksel

Tabel 1.Hasil Rekonstruksi Obyek Balok

\begin{tabular}{|c|c|c|c|}
\hline Frekuensi & $\begin{array}{c}\text { Fasa } \\
\text { rata-rata } \\
(\mathrm{rad})\end{array}$ & $\begin{array}{c}\text { Tinggi } \\
\text { Konversi } \\
(\mathrm{cm})\end{array}$ & Ketelitian(\%) \\
\hline 3 & 0,964 & 1,64 & 68,22 \\
\hline 5 & 1,720 & 1,76 & 73,19 \\
\hline 7 & 2,317 & 1,72 & 71,7 \\
\hline 9 & 2,394 & 1,35 & 56,45 \\
\hline
\end{tabular}

Obyek berundak merupakan obyek yang memiliki kedalaman yang berbeda-beda. Rekonstruksi dilakukan pada obyek agar proporsionalitas sistem dapat diketahui. Proporsionalitas sistem adalah kesebandingan perbedaan kedalaman antara obyek asli dan hasil rekonstruksinya. Pada permukaan wajah memang terdapat perbedaan kedalaman antara satu bagian dengan bagian lainnya, sehingga perlu diteliti kemampuan sistem merekonstruksi obyek yang kedalamannya beragam. Akurasi perbandingan kedalaman dan kualitas hasil rekonstruksi menjadi tolak ukur pengujian pola frinji pada penelitian awal ini.

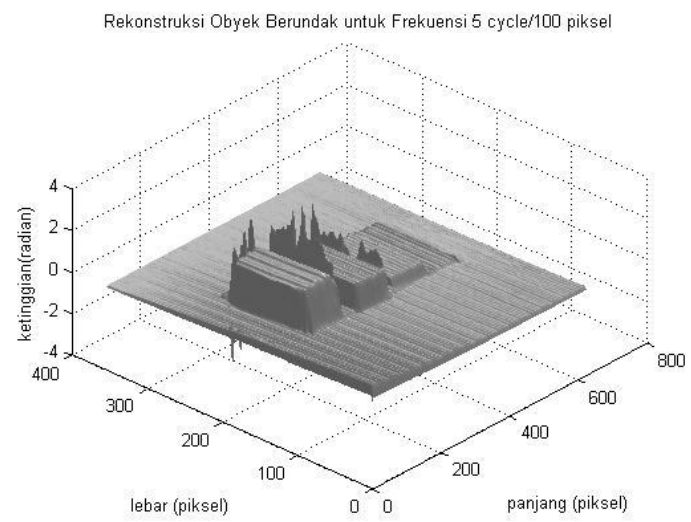

Gambar 9. Rekonstruksi Obyek Berundak Frekuensi 5 cycle/100 piksel

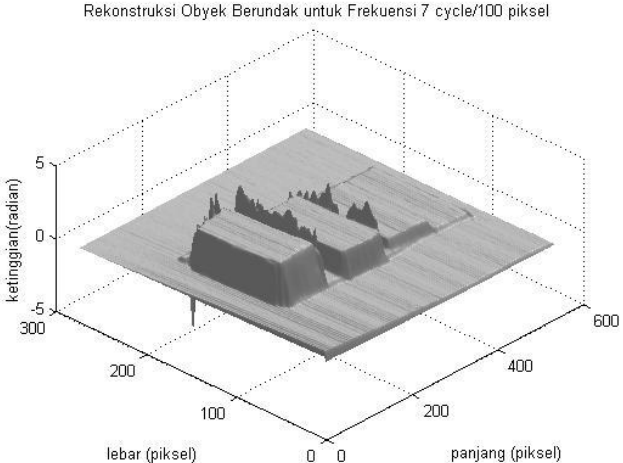

Gambar 10. Rekonstruksi Obyek Berundak Frekuensi 7 cycle/100 piksel

Tabel 2. Data Perbandingan Kedalaman untuk Rekonstruksi Obyek Berundak

\begin{tabular}{|c|c|c|c|c|}
\hline \multicolumn{2}{|c|}{ Posisi Pengukuran } & A & B & C \\
\hline \multirow{2}{*}{ Obyek Berundak } & Kedalaman(cm) & 3,2 & 1,8 & 0,8 \\
\cline { 2 - 5 } & Perbandingan & 4 & 2,25 & 1 \\
\hline \multirow{2}{*}{$\begin{array}{c}\text { Rekonstruksi 5 } \\
\text { cycle / 100 piksel }\end{array}$} & Fasa(rad) & 2,32 & 1,45 & 0,73 \\
\cline { 2 - 5 } & Perbandingan & 3,18 & 1,99 & 1 \\
\hline $\begin{array}{c}\text { Rekonstruksi 7 } \\
\text { cycle /100 piksel }\end{array}$ & Fasa(rad) & 3,1 & 1,94 & 0,98 \\
\cline { 2 - 5 } & Perbandingan & 3,15 & 1,97 & 1 \\
\hline
\end{tabular}

Melalui Tabel 2 ditampilkan hasil perbandingan kedalaman antara obyek asli dan hasil rekonstruksi. Didapatkan nilai perbandingan yang hampir identik untuk frekuensi 5 dan 7 cycle/100 piksel. Ketelitian perbandingan nilai fasa terhadap perbandingan kedalaman obyek asli bila dihitung mencapai $80 \%$ untuk kedua jenis frekuensi. Gambar 9 dan 10 menampilkan hasil rekonstruksi obyek berundak untuk frekuensifrekuensi uji. Rekonstruksi pada frekuensi yang lebih renggang yaitu 5 cycle/100 piksel memberikan noise yang lebih tajam dan permukaan balok yang bergelombang. Disisi lain, untuk rekonstruksi dengan frekuensi 7 cycle/100 piksel memberikan permukaan balok yang lebih halus dengan noise yang rendah. Melalui analisis akurasi perbandingan kedalaman dan hasil rekonstruksi obyek dipilih frekuensi 7 cycle/100 piksel yang memberikan hasil rekonstruksi yang optimum.

Penelitian awal berikutnya adalah rekonstruksi bentuk kontur. Wajah memiliki bentuk secara umum yaitu mencembung keluar. Untuk mengetahui akurasi rekonstruksi bentuk ini, dilakukan rekonstruksi terhadap obyek berbentuk setengah tabung. Selain itu, bagian penyusun wajah yang dominan yaitu hidung juga didekati rekonstruksinya dengan melakukan penelitian 
Seminar Nasional Instrumentasi, Kontrol dan Otomasi (SNIKO) 2015 Bandung, Indonesia, 10-11 Desember 2015

pada rekonstruksi obyek dengan bentuk prisma segitiga. Kemudian dilakukan analisis terhadap kesesuaian bentuk rekonstruksi dan obyek aslinya serta akurasi kedalaman obyek.

Secara bentuk, untuk obyek setengah tabung dan prisma segitiga didapatkan rekonstruksi yang sesuai dengan obyek aslinya. Hasil rekonstruksi ditampilkan secara utuh oleh Gambar 11 dan 13. Melalui penampang melintang dari tiap-tiap objek, dapat dipilih titik maksimum dari kurva 2 dimensi sebagai nilai fasa yang akan dikonversi menjadi nilai kedalaman dari rekonstruksi obyek tersebut. Penampang melintang dari masing-masing obyek ditampilkan oleh Gambar 12 dan 13. Sumbu y pada kurva tersebut adalah fasa absolut dan kemudian dikonversi menjadi kedalaman yang dianalisa akurasinya terhadap kedalaman obyek sesungguhnya.

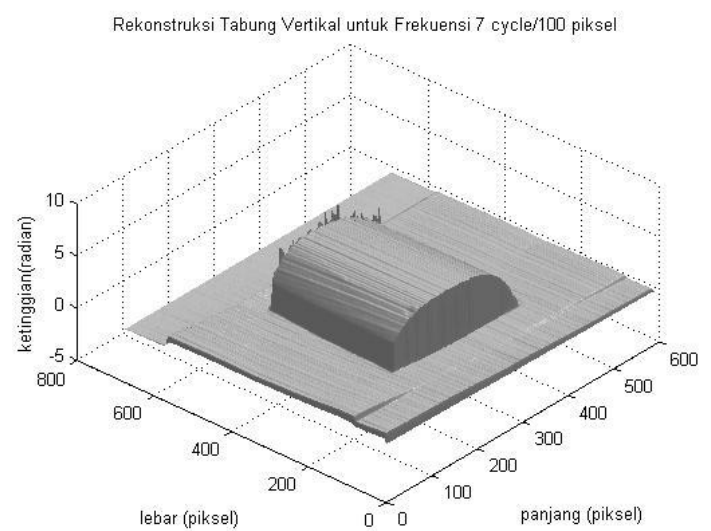

Gambar 11. Rekonstruksi Obyek Setengah Tabung dengan Frekuensi 7 cycle/100 piksel

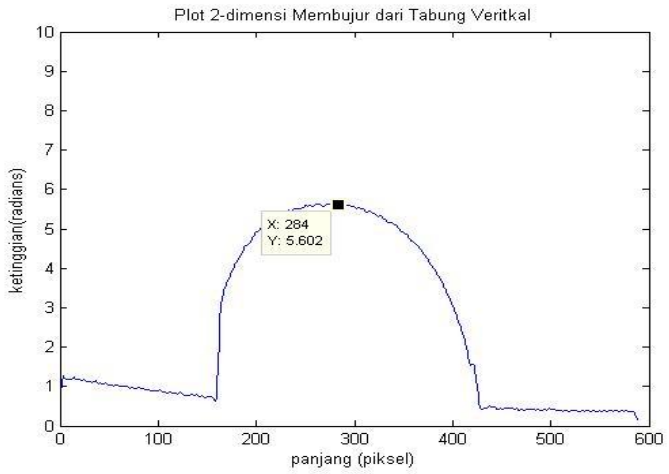

Gambar 12. Penampang Melintang dari Rekonstruksi Obyek berbentuk Setengah Tabung



Gambar 13. Rekonstruksi Obyek Prisma Segitiga dengan Frekuensi 7 cycle/100 piksel

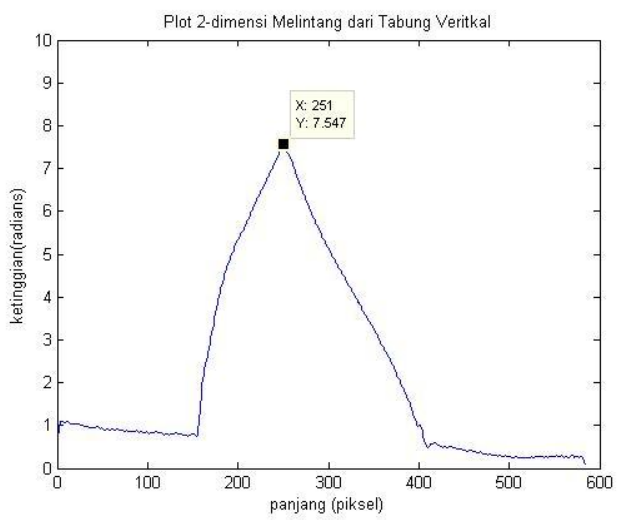

Gambar 14. Penampang Melintang dari Rekonstruks Obyek berbentuk Prisma Segitiga

Nilai dari kedalaman yang melalui konversi dibandingkan terhadap nilai kedalaman obyek sebenarnya. Data tersebut ditampilkan pada tabel 3. Untuk obyek setengah tabung ketelitian rekonstruksi mencapai $89,3 \%$ dan untuk obyek prisma segitiga dicapai ketelitian $74,67 \%$. Ketelitian-ketelitian ini konsisten dengan penelitian awal pada balok dimana didapatkan ketelitian diatas $70 \%$ pada frekuensi 7 cycle/100 piksel.

Tabel 3. Data Kedalaman Obyek Setengah Tabung dan Prisma Segitiga

\begin{tabular}{|c|c|c|c|}
\hline Obyek & $\begin{array}{c}\text { Fasa Absolut } \\
(\mathrm{rad})\end{array}$ & $\begin{array}{c}\text { Kedalaman } \\
\text { Konversi }(\mathrm{cm})\end{array}$ & Ketelitian(\%) \\
\hline $\begin{array}{c}\text { Setengah } \\
\text { Tabung }\end{array}$ & 5,602 & 4,2 & 89,3 \\
\hline $\begin{array}{c}\text { Prisma } \\
\text { Segitiga }\end{array}$ & 7,547 & 5,6 & 74,67 \\
\hline
\end{tabular}


Seminar Nasional Instrumentasi, Kontrol dan Otomasi (SNIKO) 2015 Bandung, Indonesia, 10-11 Desember 2015

Penelitian awal kemudian selesai setelah rekonstruksi pada obyek setengah tabung dan segitga. Frekuensi 7 cycle/100 piksel dipilih sebagai frekuensi optimum untuk rekonstruksi permukaan wajah pada naracoba. Kriteria yang dipenuhi adalah bentuk rekonstruksi yang proporsional,ketelitian pengukuran diatas $70 \%$, noise dengan jumlah minimal, serta kehalusan bentuk rekonstruksi.

\subsection{Penelitian pada Naracoba}

Naracoba pada penelitian ini terdiri dari 2 laki-laki yang selanjutnya akan disebut sebagai Naracoba A dan Naracoba B. Secara fisik, naracoba A memiliki bentuk wajah yang kotak, mata bulat, hidung mancung, bibir tebal dan kulit wajah putih. Naracoba B disisi lain memiliki bentuk wajah yang oval, dengan mata lebih lebar, hidung kecil, bibir tipis, dan kulit wajah gelap. Perbedaan antara kedua naracoba ini lalu dikuantifikasi pada bagian hidung. Jarak antara ujung sampai pangkal hidung untuk naracoba $A$ adalah $2,6 \mathrm{~cm}$ dan $2,4 \mathrm{~cm}$ untuk naracoba B. Naracoba A ditampilkan oleh Gambar 15 dan Naracoba B oleh Gambar 16.

Proses rekonstruksi pada wajah secara umum sama dengan proses pada penelitian awal. Tambahan pada penelitian ini adalah kedua naracoba direkonstruksi dengan menggunakan bantuan papan penutup pada bagian kepala.Sebelumnya pada uji awal naracoba, pengolahan citra gagal merekonstruksi bentuk wajah secara utuh akibat bayangan pada bagian atas dari kepala naracoba. Untuk mengantisipasi bayangan, diberikan penutup agar pengolahan data dapat menghasilkan bentuk wajah secara utuh. Selain penggunaan papan penutup, untuk rekonstruksi yang baik, obyek harus berada dalam keadaan diam saat perekaman citra. Jika obyek yaitu wajah manusia ikut bergerak ketika perekaman citra maka informasi fasa yang didapatkan tidak akan proporsional dengan bentuk obyek asli. Proses rekonstruksi untuk wajah berlangsung selama 8-10 menit bergantung pada besar citra yang akan diproses.

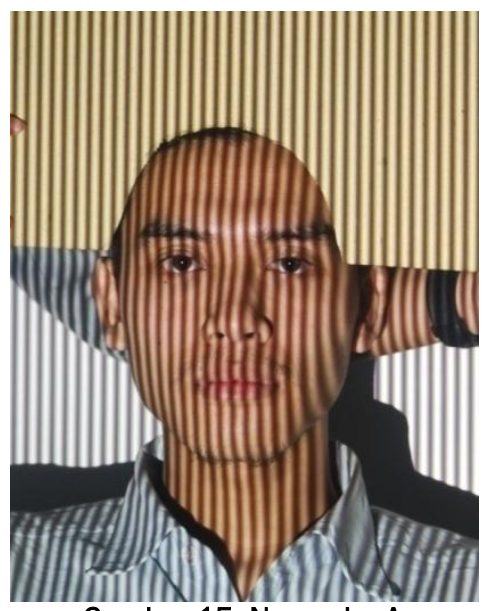

Gambar 15. Naracoba A

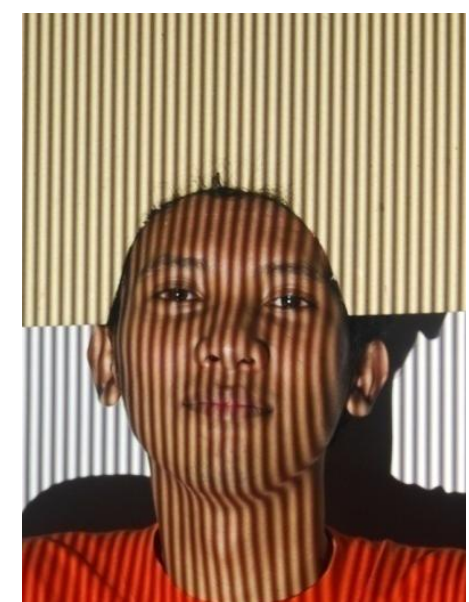

Gambar 16. Naracoba B

Hasil rekonstruksi untuk naracoba A dan B ditampilkan oleh Gambar 17 dan 18. Rekonstruksi langsung dikonversi oleh persamaan triangulasi dengan referensi titik 0 berada pada bagian papan. Sehingga sumbu $z$ pada rekonstruksi wajah langsung berada pada skala metrik yaitu $\mathrm{cm}$. Terlihat bentuk bagian-bagian penyusun wajah seperti mata,hidung, dan bibir ditampilkan secara jelas dan menggambarkan wajah naracoba sebenarnya. Pada Gambar 19 dan 20, ditampilkan penampang membujur dari rekonstruksi wajah pada bagian tengah. Terlihat bahwa profil dahi, hidung, dan bibir, direpresentasikan secara sesuai dengan tampak samping dari wajah asli seseorang. Naracoba B memposisikan kepalanya lebih mendongak dibanding naracoba A sehingga tampak lebih tinggi.

Pada rekonstruksi wajah diambil 2 titik pada bagian ujung hidung dan pangkal hidung yang akan diselisihkan lalu dibandingkan dengan jarak ujung-pangkal hidung wajah asli. Tabel 4 menampilkan perbandingan nilai antara kedalaman hidung asli dan hasil rekonstruksi. Ketelitian untuk naracoba A mencapai 90\% dan naracoba B adalah 88\%. Sehingga, dengan analisa ketelitian serta analisa bentuk rekonstruksi, profilometri frinji digital dapat digunakan sebagai teknik untuk memindai wajah secara 3-dimensi sehingga didapatkan model wajah secara utuh.

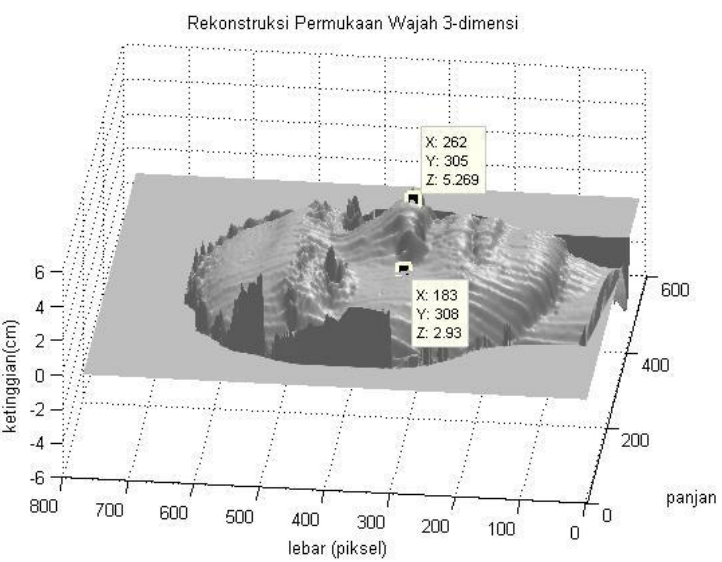

Gambar 17. Rekonstruksi Wajah Naracoba A dengan Frekuensi 7 cycle/100 piksel 


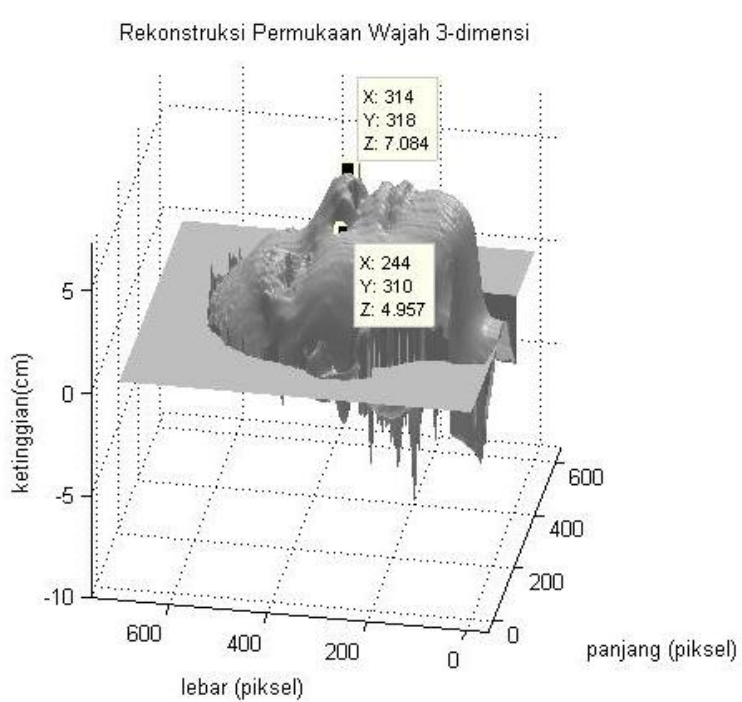

Gambar 18. Rekonstruksi Wajah Naracoba B dengan Frekuensi 7 cycle/100 piksel

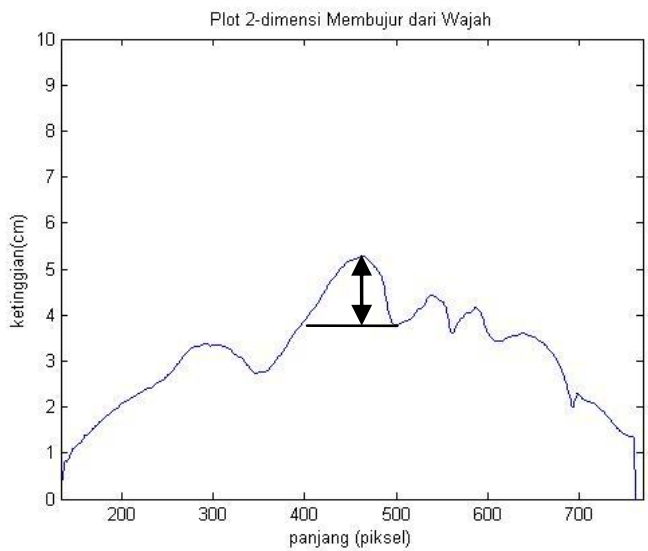

Gambar 19. Penampang Membujur dari Rekonstruksi Naracoba A

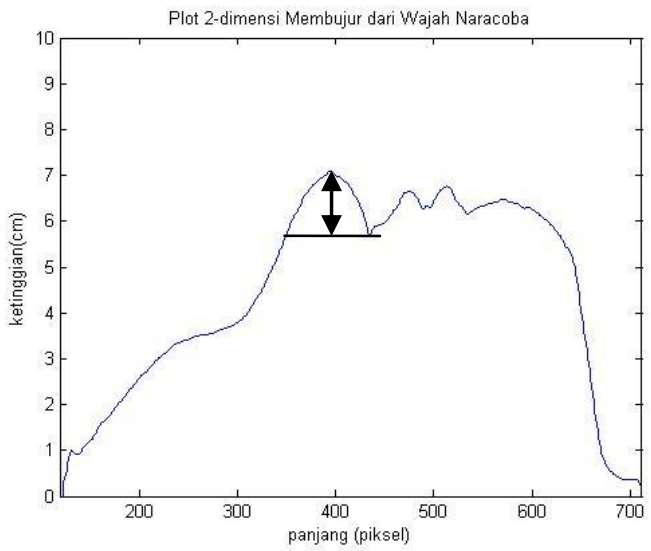

Gambar 20 Penampang Membujur dari Rekonstruksi Naracoba B
Tabel 4. Data Jarak Ujung-Pangkal Hidung Rekonstruksi Naracoba

\begin{tabular}{|c|c|c|c|}
\hline Naracoba & $\begin{array}{c}\text { Jarak Ujung- } \\
\text { Pangkal (cm) }\end{array}$ & $\begin{array}{c}\text { Jarak Hasil } \\
\text { Rekonstruksi } \\
\text { Wajah }(\mathrm{cm})\end{array}$ & $\begin{array}{c}\text { Ketelitian } \\
(\%)\end{array}$ \\
\hline A & 2,6 & 2,34 & 90 \\
\hline B & 2,4 & 2,11 & 88 \\
\hline
\end{tabular}

\section{Kesimpulan}

Telah dirancang konfigurasi sistem untuk profilometri frinji digital yang terdiri dari proyektor DLP, kamera digital, dan komputer yang dapat digunakan untuk rekonstruksi 3-dimensi profil permukaan wajah dengan informasi kedalaman pada skala metrik. Pola frinji optimum adalah dengan frekuensi 7 cycle/100 piksel untuk bisa merekonstruksi bentuk permukaan wajah baik dari segi kualitas dan keakuratan ukuran. Pada hasil rekonstruksi permukaan wajah naracoba $A$ dan $B$ diperoleh bentuk wajah yang sesuai dengan bentuk wajah asli naracoba dengan bagian-bagian penyusun wajah seperti mata,hidung,dan mulut terlihat jelas. Ketelitian pada masing-masing naracoba adalah $90 \%$ dan $88 \%$.

\section{$5 \quad$ Daftar Pustaka}

[1] L. G. Farkas, Anthropometry of the Head and Face. Raven Press, 1994.

[2] S. Goel and A. Kaushik, "A Review paper on Biometrics: Facial Recognition," Int. J. Sci. Res. Eng. Technol. IJSRET, vol. 1, no. 017, 2012.

[3] S. Zhang and P. S. Huang, "High-resolution, realtime three-dimensional shape measurement," Opt. Eng., vol. 45, no. 12, pp. 123601-123601, 2006.

[4] D. C. Ghiglia and M. D. Pritt, Two-Dimensional Phase Unwrapping. Theory, Algorithms, and Software. John Wiley \& Sons, Inc., 1998.

[5] J. M. Bioucas-Dias and G. Valadão, "Phase unwrapping via graph cuts," Image Process. IEEE Trans. On, vol. 16, no. 3, pp. 698-709, 2007.

[6] N. Zahra, "Studi Pengembangan Pencitraan Profil Permukaan Kulit dengan Teknik Profilometri Fringe Digital," Tugas Akhir, Institut Teknologi Bandung, 2013. 